\title{
JLミCOV
}

\section{Conversational marketing as a framework for interaction with the customer: Development \& validation of the conversational agent's usage scale}

\section{Khalil Israfilzade}

Vytautas Magnus University, Department of Marketing, Kaunas, Lithuania, e-mail: khalil.israfilzade@vdu.lt.

\begin{abstract}
Conversational agents are becoming an essential part of a growing number of personal and commercial encounters, bringing the issue of Conversational Marketing to a broader audience. A conversational agent is a developing technology that will be used in various fields throughout life, including e-commerce. The common characteristics of any conversational agent in whatever area are their capacity to engage in one-to-one personalised real-time dialogue with a human user and their availability 24 hours a day. Scale items for conversational agent phenomena have not been created scientifically or managerially in a business environment. The primary goal of this study was to develop and validate a new scale for conversational agents that could be used to quantify individual interactions in conversational marketing. As a result, the creation of a new scale for conversational agents with the objective of measuring individual customer interactions in conversational marketing was separated into two phases: Scale Development and Scale Validation. The Conversational Agent Usage Scale was developed and validated as a consequence of pilot studies. Additionally, this article discusses the practical consequences of conversational marketing, which can now be accomplished through the use of the Conversational Agent Usage Scale, which may be used by Customer Service \& Support, Marketing, and Sales departments.
\end{abstract}

Keywords: Conversational marketing, artificial intelligence, anthropomorphism, human-computer interaction, conversational agent

JEL codes: M3, M30, M31, M39

Citation/Atıf: ISRAFILZADE, K., (2021). Conversational marketing as a framework for interaction with the customer: Development \& validation of the conversational agent's usage scale. Journal of Life Economics. 8(4): 533-546, DOI: 10.15637/jlecon.8.4.12

Bu derginin içeriği Creative Commons Attribution-NonCommercial 4.0 Uluslararası Lisansı altında lisanslanmıştı

Content of this journal is licensed under a Creative Common Attribution-NonCommercial 4.0 International License. 


\section{INTRODUCTION}

The emergence of the Internet, the increase of big data, the explosive growth of computer science, and the enormous advancements in robotics and programming have resulted in the development of Artificial Intelligence, which enables it to handle complicated difficulties and tasks. Additionally, this technology appears to generate a variety of various types of content, including dialogues, music, poetry, artwork, film or news scripts, jokes, and creative problem-solving (Israfilzade \& Pilelienė, 2018; Akerkar, 2019; Israfilzade, 2020). Latest developments in artificial intelligence have strengthened the effectiveness of powerful tactics such as machine learning and deep neural networks (Wang \& Yuan, 2016; Hori et al., 2019; Hussain, Ameri Sianaki \& Ababneh, 2019). Numerous articles have also demonstrated the use of these techniques in conversational interfaces.

Customers now have access to information at their fingertips. Using traditional tactics, it has been challenging to retain and recruit customers with too many alternatives for better-educated customers. At the same time, in order to be effective and capable of success, any organisation must be able to conduct the business efficiently and without disruptions. The relationship between firms and customers is no longer straightforward, and with more touchpoints, it is becoming increasingly complex. Marketers today confront numerous issues in organising and managing enormous amounts of data, including truly personalised, targeted, and high-influence communication streams throughout the customer journey. Recently, eBay developed an e-commerce chatbot for Google Assistant (Thomas, 2020), which can be accessed from devices with Google Assistant by saying, "Ok Google, let me talk with eBay," allowing eBay to provide you results based on your voice search. Alternatively, to put it another way:

"Customer buying behaviours have evolved over the previous few decades."

Each digital marketing action has the potential to generate massive amounts of data in the form of clicks, visits, impressions, customer conversion rate, acquisition channel, engagement metrics, keyword phrase, pageview, behavioural profiling, transaction, geo-demographics, and emotional indicators. This is where conversational marketing may save the day by enabling the breakdown and observation of large data pools that would be impossible for a human to do alone.

Conversational marketing is a one-to-one approach that promotes significant relationships and creates value across platforms, improving customer experience, improving customer service, increasing customer engagement, and retaining customer loyalty ( $\mathrm{Xu}$ et al., 2017; Følstad \& Brandtzæg, 2017; Gentsch, 2018; Sotolongo \& Copulsky, 2018; Cancel, Gerhardt \& Devaney, 2019; Thomaz et al., 2020; Adam, Wessel \& Benlian, 2020). Conversational marketing, as opposed to traditional marketing, can use tailored messages and intelligent chatbots to communicate with clients when it is convenient for them. As a result, conversational marketing is a new way for businesses to learn and listen to their customers by engaging them through a conversational interface and satisfying their needs.

As a consequence, we may define Conversational Marketing as follows:

"Conversational marketing is centred on one-to-one interactions between a customer and an agent in real-time and as personalised as possible across many channels that creates collaborative brand experiences by enabling firms to build customer relationships and improve customer experience."

In the current paper, conversational marketing phenomena require the establishment of a scale. To have a more explicit definition of Conversational Marketing, we must construct a scale to quantify the influencing factors of the Conversational Agent (CA). Because, as mentioned previously, conversational marketing is concerned with human-computer interaction, and Conversational Agents serve as a substitute for human interaction.

It is apparent that scales for conversational agents exist in a variety of areas such as healthcare, information technology, etc. However, there is a lack of a marketing area in terms of the scale produced for the qualitative usage of the conversational agent from the standpoint of business or the customer.

That is the paper's primary research objective: to design and validate a new scale of conversational agents for use in conversational marketing to evaluate individual customers.

Consequently, further research would be devoted entirely to developing and validating the Conversational Agent Usage Scale (CAUS).

\section{THEORETICAL BACKGROUND}

Conversation is defined by the Cambridge English Dictionary (2020) as a dialogue between two or more people in which their views, feelings, and ideas are conveyed, questions are asked and answered, and news and information are shared. We see that data is communicated and that there is symmetry in that the initiative may correspond to both parties at various stages of the conversation.

"Markets are conversations" is the first premise of the Cluetrain Manifesto (Locke et al., 2001), a book 
about business-customer interaction in a networked environment. At the beginning of the book, there is a statement that "the very earliest markets were populated by persons, not abstract concepts or mathematical analysis; they were marketplaces in which supply met the demand with a handshake." For a bigger audience, the current research's primary target is to determine how this market of dialogue could be achieved by human-computer interaction instead of human-to-human connection.

The term "conversational marketing" refers to marketing that communicates with customers. This can be accomplished via live chat, chatbots, voice assistants, and other types of conversational agents. These experiences can be delivered through websites, social media channels, paid advertising, and even in-store or linked smart home devices.

Conversational marketing is highly relevant to customer relationships, especially for customer engagement (CE), as CE has been found to boost loyalty Leckie et al. 2016; Maslowska et al. 2016; Hinson et al. 2019) and customer satisfaction (Hollebeek, 2011; Calder et al. 2016; Israfilzade \& Babayev, 2020), all of which lead to higher sales (Kumar et al. 2010), assistance for peers or community members (Hinson et al. 2019; So et al. 2020), and giving a new approach of regular communication with customers. Conversational marketing tools enable marketing and sales departments to understand better what is happening on the web page and develop personalised interactions with the most qualified customers through lead reports, instant feedback from chatbots, live chat, and embedded voice calls (Akerkar, 2019; Ashfaq et al., 2020). Chung et al. (2018) investigate chatbots and customer satisfaction in the context of luxury brands and summarise that using e-commerce chatbots increases customer satisfaction with the brand, as chatbots may communicate with the customer and provide adequate customer support.

To understand Conversational AI, we must first understand the concept of AI, which enables human-machine interaction to take place in a fundamentally new way. Artificial intelligence has been around for decades, but there is still room for improvement. The simulation of the human mind by computers designed to think like people in order to mimic their actions is referred to as intelligence.

As a result, some elements distinguish conversational marketing from other customer-centric marketing tactics. Conversational marketing may sound like the current marketing effort of a particular company, with several channels and interactions with the audience. The essential difference, though, is with whom the customer is interacting. In most cases, the current customer-centric marketing technique necessitates human involvement throughout communication between the firm and the client. In the case of conversational marketing (Cancel, Gerhardt, \& Devaney, 2019), however, the one-on-one human presence is substituted by machines (Ai or non-Ai conversational agents) in interacting with potential customers with individualised product/service suggestions or offers.

To be more conceptually precise, there are mainly three types of customer interaction. Under these categories, computer-mediated communication (CMC) concepts have already been formed in academia and business, and CMC stands for computer-mediated conversation, which indicates contact between humans via the machine, not the computer alone (Muir et al., 2017). For instance, when a customer contacts a company representative via WhatsApp to express concerns about a product or service, the dialogue is mediated by computers, not humans.

Nevertheless, the conversational agent is a form of human-computer interaction (HCI) (Norman, 2017; Fitzpatrick, 2018) that combines two normally distinct scientific domains. The core concepts underpinning how users interact with chatbots are rooted in social and computer sciences. The conversational agent is a term that refers to the interaction between a human and an artificial machine via natural language. As illustrated in Table 1, a conversational agent empowered with social capabilities communicates and interacts with consumers during one-on-one customer support.

Table 1. A comparison of the three interaction types of customer communication

\begin{tabular}{|c|c|c|}
\hline $\begin{array}{c}\text { Human Human Interaction } \\
\text { (HHI) }\end{array}$ & $\begin{array}{c}\text { Computer Mediated } \\
\text { Communication (CMC) }\end{array}$ & $\begin{array}{c}\text { Human Computer } \\
\text { Interaction (HCI) }\end{array}$ \\
\hline Customer & Customer & Customer \\
\hline
\end{tabular}

Source: developed from Norman (2017), Muir et al. (2017), Fitzpatrick (2018).

These three concepts (Norman, 2017; Muir et al., 2017; Fitzpatrick, 2018) define a spectrum of user communication styles. While HHI is a dialogue between humans, CMC is also a mechanism for individuals to communicate, software programmes mediate the conversation. Finally, because HCI is defined as communication between an individual and computer software, we can argue that this distinguishes conversational marketing from other marketing approaches. 


\section{METHOD}

Given how contemporary research is being created and how different forms of data relate at various times, it seemed appropriate to utilise a quantitatively driven design as a mixed method. One of the primary objectives of this study was to develop a new scale of conversational agents to quantify individual experiences in conversational marketing.

A cross-sectional study design is utilised, namely survey research, and an independent research organisation is used to collect data. To accomplish the defined research objective and to accomplish the stated objective, the following research methods are used: expert panel content analysis, questionnaire survey, descriptive statistical analysis, reliability analysis, and exploratory factor analysis for scale development and validation.

\subsection{Scale Development}

Numerous measuring scales have been developed throughout the years to evaluate behaviours, techniques, and approaches in various research activities. Measuring is a fundamental scientific method that enables researchers to learn about individuals, objects, events, and mechanisms. Measurement scales are valuable tools for explicitly assigning numerical values to phenomena that can be quantified.

A primary objective of this work is to develop a new scale for conversational agents in order to measure individual encounters in conversational marketing. To do this, a Framework for Systematic Scale Creation was examined using the three methods provided by Churchill (1979), Netermeyer et al. (2003), and DeVellis (2005). While the terminology used in each of the three systems varies slightly, the fundamental concepts and steps involved are essentially similar. The conversational agent scale was developed using the eight phases given by DeVellis (2017). Devellis (2017) recommends eight measures to consider when developing the scale, which is detailed in Figure 1.

\subsubsection{Identification and generation of scale items}

A review of scientific literature was conducted to identify factors that influence the quality and usability of conversational agents (Table 2). Because the research object of the work is a text-based conversational agent, voice-based conversational agents (e.g. Siri) and general AI (capable of performing some kind of human task), related factors were not included in the theoretical frame of reference for the identification procedure of this research paper (e.g. chatbots). As a result of this theoretical and conceptual framework, a new scale of the conversational agent's quality of use has been developed and appropriately classified as follows: Anthropomorphism (human-likeness), Personalised interaction, Permission marketing, Real-time interaction, Conversational Agent types and Conversational Agent platforms.

The first stage entails creating a large pool of theoretical and practical items that could be included in the scale (DeVellis, 2017). Authors created a broad item pool by using well-established scale construction criteria (Churchill, 1979; DeVellis, 2017). As part of the data provided by related literature, an initial list of 28

Figure 1. Stages of Scale Development

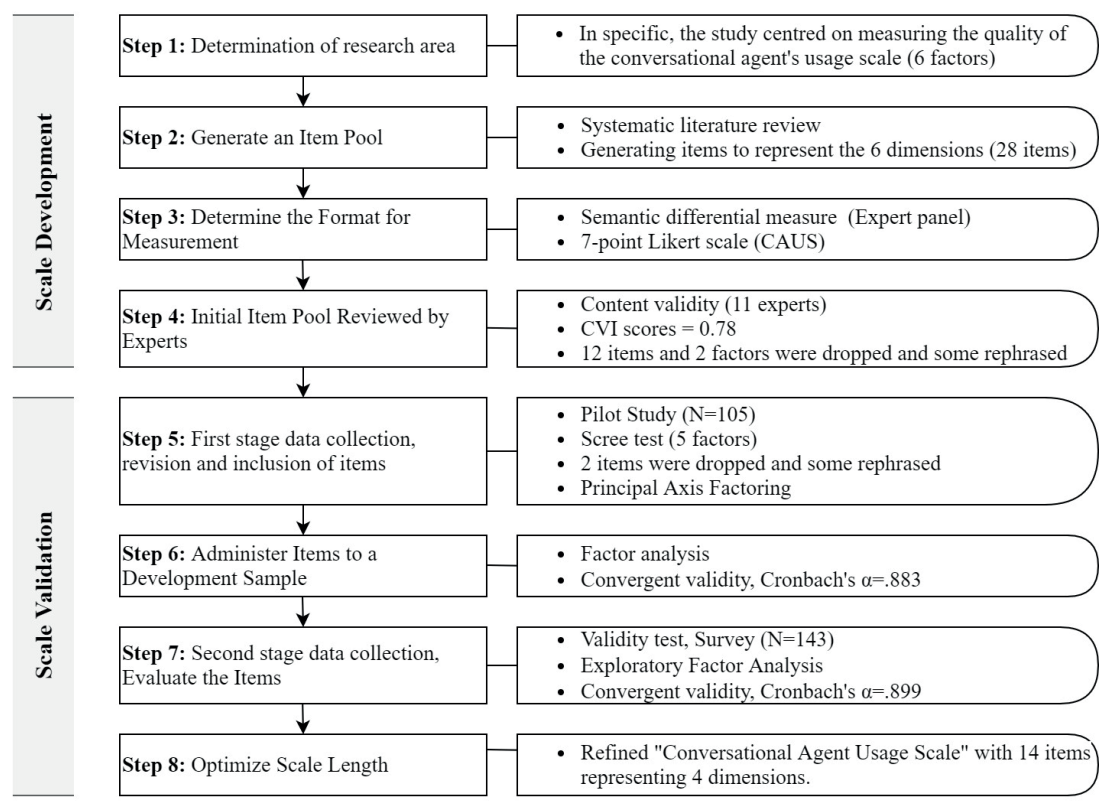

Source: adopted and developed from DeVellis (2017) 
items was established (Appendix 1).

As Appendix 1 indicates, anthropomorphism encompasses eleven distinct components that demonstrate the critical role fact plays in the conversational agent. Determining the chatbots' human-like nature in human-computer interaction would provide a more detailed evaluation of the perceived anthropomorphism associated with the chatbot's use.

\subsubsection{Determination and evaluation of the initial items by Experts}

To exclude unnecessary items from the pool and to determine authors' perceived biases, initial items were reviewed by a panel of experts, including eleven experts on conversational marketing platforms. Pursuing expert assessment serves to ensure the authenticity of the material or, more simply, the content's validity. Yusoff's (2019) content validity technique, which consists of six steps, was followed for the current process of expert identification and evaluation of the initial items. The six stages of content validation are as follows: 1) development of the conversational agent's content validation form; 2) gathering expert review panels in conversational agent platforms; 3) conducting content validation; 4) domain and item analysis; 5) provision of ratings for each item; and 6) CVI measurement.

Following the design of the conversational agent's content validation form, the expert assessment panels on the conversational agent platforms are often selected based on their individual understanding of the subject being analysed. As a result, it is clear that conversational marketing is a relatively new concept, and contacting industry experts who are already experienced in designing and producing chatbots for various networks seems more legitimate than comparing academic experts in this field, which has received little attention. An electronic content validation form is submitted to conversational marketing experts for this non-face-to-face strategy. Experts are then requested to evaluate the domain and its items objectively before providing a score to each item.

The Content Validity Index (CVI) can be used to evaluate content validation proof, and there are two forms of CVI (Appendix 2), CVI for the item (I-CVI) and CVI for scale (S-CVI). After determining the Content Validity Index for Items (I-CVI), the ratio of content experts delivering a significance value of 9 or 10 is considered as an agreed item, with the measurement formula being "I-CVI = (agreed item)/ (number of experts (e.g., 11 experts)" According to Lynn (1986), the appropriate CVI values for at least nine experts are at least 0.78 . Dimensions that received high marks from 10 or more experts were chosen for further investigation.

Utilising an I-CVI of no less than 0.78 as a result, a collection of 16 items has been assembled, covering a total of 6 dimensions. Simultaneously to the item validation, the expert evaluated the dimension, and at the conclusion of the expert analysis, four dimensions are consolidated into two dimensions. The primary explanation for this behaviour was that these dimensions shared specific characteristics that could be combined into one dimensionality. As a result, Personalized Real-Time Interaction emerged from the Personalised Interaction and Real-Time Interaction dimensions. CA types and platforms are formed by combining the dimensions of CA types and CA platforms.

Table 2. List of Primary Factors for the Quality of CAUS

\begin{tabular}{|c|c|c|}
\hline No & Dimensions & Sources \\
\hline 1 & $\begin{array}{l}\text { Anthropomorphism } \\
\text { (human-likeness) }\end{array}$ & $\begin{array}{l}\text { Saygin et. al. (2011); Xu et al. (2017); Damiano \& Dumouchel (2018); } \\
\text { Lebeuf (2018); Pfeuffer et. al. (2019); Elsholz et al., (2019); Ciechanowski } \\
\text { et. al. (2019); Thomaz et al. (2020); Adam, Wessel \& Benlian (2020) }\end{array}$ \\
\hline 2 & $\begin{array}{l}\text { Personalised } \\
\text { interaction }\end{array}$ & $\begin{array}{l}\text { Zadrozny (2000); Kuligowska (2015); Aguirre et al., (2016); Banchs } \\
\text { (2017); Duijst (2017); Shum et al. (2018); Cancel, Gerhardt \& Devaney } \\
\text { (2019); Elsholz et al. (2019); Thomaz et al. (2020) }\end{array}$ \\
\hline 3 & $\begin{array}{l}\text { Permission } \\
\text { marketing }\end{array}$ & $\begin{array}{l}\text { Touré-Tillery \& McGill (2015); Krafft, Arden \& Verhoef (2017); Følstad } \\
\text { et. al. (2018); van Pinxteren et al. (2019); Thomaz et al. (2020); Hong, } \\
\text { Choi \& Williams (2020) }\end{array}$ \\
\hline 4 & $\begin{array}{l}\text { Real-time } \\
\text { interaction }\end{array}$ & $\begin{array}{l}\text { Cui et. al. (2017); Gnewuch et al. (2017); Gaetano \& Diliberto (2018); } \\
\text { Gentsch (2018); Atiyah, Jusoh \& Almajali (2018); Ciechanowski et. al. } \\
\text { (2019); Luo et. al. (2019); Akerkar (2019); Cancel, Gerhardt \& Devaney } \\
\text { (2019) }\end{array}$ \\
\hline 5 & $\begin{array}{l}\text { Conversational } \\
\text { Agent types }\end{array}$ & $\begin{array}{l}\text { Schuetzler et al. (2014); Kuligowska (2015); Ramesh et al. (2017); Lebeuf } \\
\text { (2018); Sotolongo \& Copulsky (2018); Hussain, Ameri Sianaki \& } \\
\text { Ababneh (2019); Cancel, Gerhardt \& Devaney (2019), Almansor \& } \\
\text { Hussain (2020); Bavaresco et al. (2020) }\end{array}$ \\
\hline 6 & $\begin{array}{l}\text { Conversational } \\
\text { Agent platforms }\end{array}$ & $\begin{array}{l}\text { Kuligowska (2015); Cui et. al. (2017); Yin, Chang \& Zhang (2017); } \\
\text { Sotolongo \& Copulsky (2018); Lebeuf, (2018); Gentsch (2018); Cancel, } \\
\text { Gerhardt \& Devaney (2019) }\end{array}$ \\
\hline
\end{tabular}




\subsection{Scale Validation}

\subsubsection{The first stage, assessment for validity}

According to Netemeyer et al. (2003), pilot research reduced the number of items by deleting or changing those that did not meet the testing conditions mentioned prior to this study. As a result of this assumption, the Exploratory Factor Analysis was shown to be more efficient in the current stage of scale development for the purification of survey questions, as indicated by DeVellis (2017). The Exploratory Factor Analysis method is carried out in three steps, as described by Ferguson and Cox's EFA Users' Guide in 1979. Pre-analysis, extraction, and rotation tests are among these steps.

Based on expert panel validation, sixteen questions were prepared and delivered in a survey encompassing four factors that respondents participated in on the first day of the survey during the September 2020 timeframe. Participants were employed by the Azerbaijan-based organisation "Bimpact" (bimpact.az/en), which provides marketing and business analysis, management consulting, and data collecting and research services.

Based on the respondent demographic profile (Table 4 ), it is possible to assume that the majority of respondents are between the ages of 18 and 35, accounting for over 77 per cent of responses (total sample size $\mathrm{n}=105)$.

Table 4. Respondents demographic profile

\begin{tabular}{|c|c|c|c|}
\hline Measure & Characteristics & Frequency & Percent \\
\hline \multicolumn{3}{|l|}{ Total sample } & $(N=105)$ \\
\hline \multirow[t]{2}{*}{ Gender } & Males & 59 & $56 \%$ \\
\hline & Females & 46 & $44 \%$ \\
\hline \multirow[t]{4}{*}{ Age } & From 18 to 25 years & 42 & $40 \%$ \\
\hline & From 26 to 35 years & 39 & $37 \%$ \\
\hline & From 36 to 45 years & 18 & $17 \%$ \\
\hline & Over 46 years & 6 & $6 \%$ \\
\hline \multirow[t]{4}{*}{ Education } & Associate degree & 9 & $9 \%$ \\
\hline & Bachelor's degree & 59 & $56 \%$ \\
\hline & Master's degree & 33 & $31 \%$ \\
\hline & Doctoral degree & 4 & $4 \%$ \\
\hline
\end{tabular}

Respondents were asked to judge the quality of their interaction with chatbots when they interacted with machines (bots) in the capacity of a brand representative in order to elicit memories of their most recent engagement with CA. The CA's measuring scale consisted of sixteen items, and the seven-point Likert scale was used to generate more complete responses. Seven-point Likert scales are sensitive enough to provide a more accurate assessment of participants and are more suited for digital distribution (Finstad, 2010). Each item was directly responded to on a seven-point Likert scale ranging from Strongly Agree to Strongly Disagree, where a score of 1 indicates strong disagre- ement with the argument and a score of 7 indicates complete agreement with the statement.

Prior to doing the factor analysis, the dataset's suitability for factor analysis was determined through a series of trials. The adequacy of the 16 questionnaire items' measurements was determined through the use of descriptive analysis (Appendix 3). While the distribution was confirmed to be expected, Kaiser-Meyer-Olkin (KMO) and Bartlett analyses were used to determine whether the measure is suitable for factor analysis of the consistency of use of the conversational agent metric. Both the KMO and Bartlett sphericity analyses were found to be significant in all predictor variables $(\mathrm{p}<0.001)$, and it was assumed that the measurement should be employed for factor analysis (Appendix 4).

The item was extracted using Principal Axis Factoring (PAF) rather than Principal Component Analysis (PCA), which are typically distinct variants of the same analysis rather than two distinct approaches. According to the initial commonality coefficient (Appendix 5), there are variables with a low communality coefficient, namely PER_NONS (.214), CA_DYNAMI (.181). The following step was to do Scree analyses in order to extract additional factors. According to the Scree Plot result, five factors were extracted rather than four, indicating that item(s) correlate differently than established factors. Total Variation Explained demonstrates that extracting five factors explains 66.4 per cent of the common variance (Appendix 6), whereas four factors explain 61.3 per cent.

Furthermore, using the average inter-item correlation, it was determined that two variables, PER_NONS and CA_DYNAMI, were critical in explaining why the Scree test indicated five rather than four factors. Cronbach analyses also revealed that removing the items improves group correlation. In terms of developing (CAUS) instruments, based on DeVellis (2017) Scale Development Guidelines, items 19 (PER_NONS; Chatbots will provide me with responses on a 7/24/365 basis) and 24 (CA_DYNAMI; the ability of chatbots to be modified by external powers enables me to establish positive standards of use during the machine conversation) have been eliminated.

The rotating factor structure resulted in a four-factor structure with no factors containing fewer than two items and no cross-loading items. According to "Total Variation Explained," the extraction of four variables accounts for 69.8 per cent of the normal variance (Appendix 7), implying that the four-factor design is critical and the approach is appropriate. According to each aspect, the proportions explained were 20.29 per cent (Anthropomorphism), 18.98 per cent (CA types and platforms), 18.95 per cent (Personalized Real-Time Interaction), and 11.53 per cent (Permission Marketing). 
Table 5. Cronbach's Alpha for each element of the quality of the CAUS instrument

\begin{tabular}{r|lll}
\hline & $\begin{array}{l}\text { Cronbach's } \\
\text { Alpha }\end{array}$ & $\begin{array}{l}\text { Cronbach's Alpha Based } \\
\text { on Standardized Items }\end{array}$ & $\begin{array}{l}\text { Number of } \\
\text { items }\end{array}$ \\
\hline Anthropomorphism (human-likeness) & .897 & .898 & 4 \\
Personalized Real-Time Interaction & .889 & .890 & 4 \\
Permission marketing & .872 & .873 & 2 \\
CA types and platforms & .870 & .871 & 4 \\
\hline CAUS instrument & .883 & & 14 \\
\hline
\end{tabular}

For the reliability of the conversational agent's usage (CAUS) instrument, an item analysis was used to examine the reliability of each consistency factor. The overall reliability of the scale has also been confirmed to be $\alpha=.883$ for the CAUS instrument as a result of the purification process (Table 5).

\subsubsection{The second stage, evaluation and optimisation of the scale items}

Fourteen items were constructed and disseminated in survey questionnaires to respondents throughout the October 2020 period following the pilot study's purification. Participants were recruited by the company
"Bimpact," and the questionnaire was distributed in exchange via online, with only those who have previously utilised chatbot services participating. It should be noted that the prior pilot study's essential consideration was the elimination of items that were provided, and that the previous study's respondent was not authorised to participate in the present questionnaire.

Because each item in the prior pilot study had 5 to 10 participants, a total of 16 things would require between 80 and 160 people. The second study's sample size $(\mathrm{N}=143)$ is large enough to produce accurate outcome statistics while doing factor analysis (Table 6).

Table 6. Respondents demographic profile of the 2nd Study

\begin{tabular}{r|l|r|r}
\hline Measure & Characteristics & Frequency & \multicolumn{2}{c}{ Percent } \\
\hline \multicolumn{2}{c|}{ Total sample } & \multicolumn{3}{|c}{$(N=143)$} \\
\hline Gender & Males & 84 & $59 \%$ \\
& Females & 59 & $41 \%$ \\
\hline \multirow{2}{*}{ Age } & From 18 to 25 years & 63 & $44 \%$ \\
& From 26 to 35 years & 47 & $33 \%$ \\
& From 36 to 45 years & 23 & $16 \%$ \\
& Over 46 years & 10 & $7 \%$ \\
\hline Education & Associate degree & 12 & $8 \%$ \\
& Bachelor's degree & 86 & $60 \%$ \\
& Master's degree & 42 & $29 \%$ \\
& Doctoral degree & 3 & $2 \%$ \\
\hline
\end{tabular}

Table 7. Scales summary (factor loadings across studies)

\begin{tabular}{|c|c|c|}
\hline Scale items & EFA pilot study & EFA 2nd study \\
\hline \multicolumn{3}{|l|}{ Factor 1: Anthropomorphism } \\
\hline Personality (ANT_PERSON) & .893 & .719 \\
\hline Emotions (ANT_EMOTIO) & .801 & .756 \\
\hline Professional appearance (ANT_APPEAR) & .777 & .911 \\
\hline Language style (ANT_LANGUA) & .746 & .757 \\
\hline \multicolumn{3}{|l|}{ Factor 2: Personalized Real-Time Interaction } \\
\hline Recommendation engines (PER_RECOMM) & .792 & .766 \\
\hline Interpretation of the user request (PER_INTERPE) & .871 & .660 \\
\hline Advise in the request of the user (PER_ADVICE) & .692 & .851 \\
\hline 7/24/365 response (PER_NONS) & .056 & \\
\hline Automated response (PER_AUTOMA) & .697 & .665 \\
\hline \multicolumn{3}{|l|}{ Factor 3: Permission marketing } \\
\hline Data privacy (PMA_DATAPR) & .826 & .748 \\
\hline Trust (PMA_TRUST) & .842 & .878 \\
\hline \multicolumn{3}{|l|}{ Factor 4: CA types and platforms } \\
\hline Knowledge-based (CA_KNOWLE) & .877 & .768 \\
\hline Goals (CA_GOALS) & .690 & .647 \\
\hline Design approach $\left(C A \_D E S I G N\right)$ & .693 & .756 \\
\hline Dynamism (static, dynamic) (CA_DYNAMI) & -.014 & \\
\hline Social platforms (CA_SOCPLA) & .730 & .854 \\
\hline Total Items & 16 & 14 \\
\hline Cronbach's Alpha & 0.88 & 0.90 \\
\hline
\end{tabular}


Table 7. Scales summary (factor loadings across studies)

In terms of the currents stage, each parameter aligns with the normality of the distribution (Appendix 8), which was checked by skewness and kurtosis inspection prior to the exploratory factor analysis, as it occurred in the pilot study. Although the distribution normality has been tested, the CAUS instrument has also been subjected to Kaiser-Meyer-Olkin (KMO) and Bartlett tests. Both KMO analysis 0,839 and the Bartlett sphericity analysis were shown to be significant in all predictor variables $(\mathrm{p}<0.001)$, and it was proposed that the calculation be used for factor analysis.

The term "Total Variance Explained" indicates that the extraction of four variables accounts for 70.1 per cent of the standard variance (Appendix 9), implying that the four-factor model is adequate and the approach satisfactory. Each element clarified 20.36 per cent (Anthropomorphism), 20.23 per cent (CA styles and platforms), 18.14 per cent (Personalized Real-Time In- teraction), and 11.37 per cent (Permission Marketing) of the total.

The 14 items that were available after the preliminary EFA (pilot study) were used in the following EFA to see how removing misleadingly worded items, and cross-loading items affected the results. The EFA's findings are given in Table 7, which demonstrates that the EFA yielded four dimensions.

For the accuracy of the CAUS instrument's quality, an item analysis was performed to determine the reliability of each accuracy factor. The total reliability of the scale was evaluated to be $\alpha=.890$ for the CAU instrument as a result of the purification procedure (Table 8), increased from $\alpha=.883$ in the pilot study. Internal accuracy should be between 0.7 and 0.9 , according to Blunch (2008), with all four elements in this calculation offering a sufficient level of reliability.

Following two studies on the quality of the Conversational Agent's Usage Scale, it could be determined

Table 8. Cronbach's Alpha of the 2nd Study for each element of the quality of the CAUS instrument

\begin{tabular}{r|lll}
\hline & $\begin{array}{l}\text { Cronbach's } \\
\text { Alpha }\end{array}$ & $\begin{array}{l}\text { Cronbach's Alpha Based } \\
\text { on Standardized Items }\end{array}$ & $\begin{array}{l}\text { Number of } \\
\text { items }\end{array}$ \\
\hline Anthropomorphism (human-likeness) & 0.891 & 0.891 & 4 \\
Personalized Real-Time Interaction & 0.873 & 0.874 & 4 \\
Permission marketing & 0.861 & 0.862 & 2 \\
CA types and platforms & 0.892 & 0.893 & 4 \\
\hline CAUS instrument & 0.899 & & 14 \\
\hline
\end{tabular}

Table 9. The final form of Conversational Agent's Usage Scale

\begin{tabular}{|c|c|}
\hline \multicolumn{2}{|r|}{ Anthropomorphism (human-likeness) } \\
\hline Personality & $\begin{array}{l}\text { The chatbot's personality allows me to set positive expectations of the machine's } \\
\text { quality of use during the conversation. }\end{array}$ \\
\hline Emotions & $\begin{array}{l}\text { Showing the emotional connection of the chatbot allows me to set positive } \\
\text { expectations of the quality of use during the conversation with the machine. }\end{array}$ \\
\hline Professional appearance & $\begin{array}{l}\text { The professional appearance of the chatbot allows me to set positive expectations } \\
\text { of the quality of use during the conversation with the machine. }\end{array}$ \\
\hline Language style & $\begin{array}{l}\text { The language style of the chatbot allows me to set positive expectations of the } \\
\text { quality of use during the conversation with the machine. }\end{array}$ \\
\hline \multicolumn{2}{|r|}{ Personalised Real-Time Interaction } \\
\hline Recommendation engines & $\begin{array}{l}\text { Chatbots can provide me with content (product/service) recommendations } \\
\text { tailored to my preferences. }\end{array}$ \\
\hline $\begin{array}{l}\text { Interpretation of the user } \\
\text { request }\end{array}$ & Chatbots can interpret my request tailored to my preferences. \\
\hline $\begin{array}{l}\text { The advice in the request of } \\
\text { the user }\end{array}$ & Chatbots can provide me with personalised advice in the request of the mine \\
\hline Automated response & Chatbots can provide me with a relevant automated response. \\
\hline \multicolumn{2}{|r|}{ Permission marketing } \\
\hline Data privacy & $\begin{array}{l}\text { I would probably disclose the required information for the chatbot because of the } \\
\text { data transparency of chatbots. }\end{array}$ \\
\hline Trust & $\begin{array}{l}\text { Competentness and effectiveness in handling all my interactions with chatbot } \\
\text { make me trust it. }\end{array}$ \\
\hline \multicolumn{2}{|r|}{ CA types and platforms } \\
\hline Knowledge-based & $\begin{array}{l}\text { The ability of chatbots to communicate efficiently in natural language allows me } \\
\text { to set positive expectations of the quality of use during the conversation with the } \\
\text { machine. }\end{array}$ \\
\hline Goals & $\begin{array}{l}\text { Chatbots help me accomplish my task or perform a particular task in a specific } \\
\text { area (e.g., booking, purchasing, ordering food, arranging an event). }\end{array}$ \\
\hline Design approach & $\begin{array}{l}\text { The ability of chatbots to be knowledgeable and imaginative enough allows me to } \\
\text { set positive expectations of the quality of use during the conversation with the } \\
\text { machine. }\end{array}$ \\
\hline Social platforms & $\begin{array}{l}\text { Interacting with chatbots in the messenger (e.g., Facebook messenger) leads to a } \\
\text { higher quality of use during the conversation with the machine. }\end{array}$ \\
\hline
\end{tabular}


that it is valid for measuring customer interactions with the machine and therefore useful for commonly used applications within the scope of the customer relationship and customer engagement. Table 9 depicts the CAUS's finalised structure and content.

Furthermore, the CAUS instrument has proven to be helpful in anticipating customer preferences in order to give more perceived value during a dialogue with the conversational agent.

\section{DISCUSSION AND CONCLUSIONS}

Scale items for the phenomena of the conversational agent have not been developed in a scientific or managerial approach in a business context. The paper's primary objective was to provide a new scale for conversational agents in order to measure individual encounters in conversational marketing. A Systematic Scale Creation Framework (Churchill, 1979; Netermeyer et al., 2003; DeVellis, 2005) was used to attain this aim. Consequently, the development of a new scale of conversational agents for the purpose of evaluating individual consumer involvement in conversational marketing was divided into two phases: Scale Development and Scale Validation. Eleven specialists from various conversational marketing platforms are collaborating in the scale development study's content validation. Following expert panel validation, sixteen questions were developed and delivered in a survey addressing four factors in which respondents participate as part of pilot research. As a result of these pilot studies, the Conversational Agent Usage Scale was developed and validated.

It can be assumed that it is helpful in assessing consumer interactions with the machine and, therefore, crucial for generalised usages within the scope of the customer relationship. Furthermore, the CAUS instrument has proved to be useful in predicting customer demands in order to provide a more significant perceived advantage during a machine encounter.

Brands that finally succeed with conversational interfaces will also achieve their own goal of becoming more customer-centric. They will develop the ability to communicate with their consumers in their native language, anticipate their requirements, satisfy them at scale, and optimise each contact in order to expand their relationships and earnings.

Marketers may now provide two-way engagement with a high degree of personalisation and feedback, resulting in collaborative brand experiences. This advancement of technology and new techniques will enable marketers to achieve superior commercial results, better understand their consumers' demands, and devote more time to campaign planning and creative creation.

\section{Managerial Implications}

This article also examines the practical implications of conversational marketing, which may now be achieved through the usage of the Conversational Agent Usage Scale. The list below highlights the most important consequences of our new scale:

Customer Service \& Support. Customer service representatives employ conversational communications strategies to engage with website visitors who use the function to answer questions or resolve concerns. These technologies allow members of the customer service staff to be influential during the day. The Conversational Agent Usage Scale can assist customer service personnel in quickly addressing fundamental problems, giving them greater freedom in answering more complex queries. In other words, having the scale will allow businesses to tailor their conversational agent (e.g., chatbot) to meet the needs of their consumers depending on their preferences. Moreover, corporations may discover where their agent falls short, whether it is Anthropomorphist qualities such as the professional appearance of the agent or exhibiting some emotionality that allows connection with particular consumers.

Marketing departments. Through lead information, quick feedback, and bots, marketing departments utilise conversational marketing software to analyse what is happening on their platform and to build a personalised touchpoint with their most qualified prospects. Simply put, our scale enables marketing managers to manage conversations in order to identify active users on social media or product pages, respond to questions or queries, identify the best promotional products available, and direct consumers to online payment or sales associates to complete purchases.

Additionally, the Scale of Conversational Agent Usage is more than a scale. Similarly, it may be applied to a wide variety of commercial functions, including e-mail marketing, forms, landing pages, and FAQs.

Sales Department. Sales teams employ conversational marketing tactics to generate leads and shorten the sales cycle. In today's digital age, an increasing number of consumers are making purchases from online businesses to meet their buying demands. The number of visits to an e-commerce website is growing by the day. Conversational Agent assists in serving consumers by offering them with high-quality and efficient service. After utilising scale, agents might also be able to assist the sales team in performing better, and it automates sales, resulting in increased online sales and income for the firm, particularly in the B2B sector. Because, as we all know, most sales managers devote a significant amount of effort to identifying prospective sales and filtering inquiries from corporate customers. This scale has the ability to enable managers to categorise and 
target potential business customers.

Eventually, Customers expect their experience to be personalised to their own requirements and desires. Conversational marketing is an excellent approach to accomplish this without significantly altering a brand's overall marketing strategy.

\subsection{Future works and Limitations}

In terms of potential future research and practice, we have developed a Conversational Agent Usage measurement scale and primary factors of conversational marketing measurement scale, which add to our understanding of the essence and dimensionality of the 'conversational marketing' definition within the larger theoretical field of interactive human-computer interaction.

By presenting a Conversational Agent Usage Scale framework and a corresponding diagnostic approach, this work provides a range of exploratory insights into the core and complexity of this emergent term. As a result, it would be more beneficial for future studies if researchers could include or simply modify dimensions, as this phenomenon is still in its early stages.

Furthermore, as conversational marketing gains momentum, the range of ethical problems around human-computer interaction grows. While ethics is a well-established field, human-computer interaction raises issues about the settings in which humans and artificial agents coexist, which are compounded by the significant number of agents now produced in human communities and businesses.

Limitations. Regardless of the research's novelty, certain limitations may serve as motivation for more investigation.

Therefore, doing research on voice-based conversational bots (e.g. Siri, Cortona) or Artificial General Intelligence is challenging (AI capable of performing any type of human task). Due to the complex nature of these conversational entities and their continued uncertainty in terms of study topics.

Another limitation was the sample's age distribution; in our research, the majority of participants were young. As a result, the age of the respondents was not evenly distributed among the various ages.

\section{REFERENCES}

ADAM, M., WESSEL, M., \& BENLIAN, A. (2020). AI-based chatbots in customer service and their effects on user compliance. Electronic Markets, 1-19.

AGUIRRE, E., ROGGEVEEN, A. L., Grewal, D., \& Wetzels, M. (2016). The personalisation-privacy paradox: implications for new media. Journal of Consumer Marketing.

AKERKAR, R. (2019). Artificial Intelligence for Business. SpringerBriefs in Business. doi:10.1007/978-3-319-97436-1

ALMANSOR, E. H., \& HUSSAIN, F. K. (2020). Survey on Intelligent Chatbots: State-of-the-Art and Future Research Directions. In L. Barolli, F. K. Hussain, \& M. Ikeda (Eds.), Advances in Intelligent Systems and Computing. Complex, Intelligent, and Software Intensive Systems (Vol. 993, pp. 534-543). Cham: Springer International Publishing. https://doi.org/10.1007/978-3-030-22354-0_47

ASHFAQ, M., YUN, J., YU, S., \& LOUREIRO, S. M. C. (2020). I, Chatbot: Modeling the determinants of users' satisfaction and continuance intention of AI-powered service agents. Telematics and Informatics, 54, 101473.

ATIYAH, A., JUSOH, S., \& ALMAJALI, S. (2018, July). An efficient search for context-based chatbots. In 2018 8th International Conference on Computer Science and Information Technology (CSIT) (pp. 125-130). IEEE.

BANCHS, R. E. (2017, December). On the construction of more human-like chatbots: Affect and emotion analysis of movie dialogue data. In 2017 Asia-Pacific Signal and Information Processing Association Annual Summit and Conference (APSIPA ASC) (pp. 1364-1367). IEEE.

BAVARESCO, R., SILVEIRA, D., REIS, E., BARBOSA, J., RIGHI, R., COSTA, C., ANTUNES, R., GOMES, M., Gatti, C., Vanzin, M. and Silva, E., (2020). Conversational agents in business: A systematic literature review and future research directions. Computer Science Review, 36, p.100239.

BLUNCH, N. (2008). Introduction to Structural Equation Modelling Using SPSS and AMOS. doi:10.4135/9781446249345

CALDER, B. J., ISAAC, M. S., \& MALTHOUSE, E. C. (2016). How to capture consumer experiences: A context-specific approach to measuring engagement: Predicting consumer behavior across qualitatively different experiences. Journal of Advertising Research, 56(1), 39-52.

CAMBRIDGE ENGLISH DICTIONARY (2020). Conversation. CONVERSATION | meaning in the Cambridge English Dictionary. https://dictionary.cambridge.org/dictionary/english/conversation? $\mathrm{q}=$ Conversation.

CANCEL, D., GERHARDT, D., \& DEVANEY, E. (2019). Conversational marketing: How the world's fastest growing companies use chatbots to generate leads 24/7/365 (and how you can too). Hoboken, NJ: Wiley.

CHUNG, M., Ko, E., JOUNG, H. and KIM, S.J., (2020). Chatbot e-service and customer satisfaction regarding luxury brands. Journal of Business Research, 117, pp.587-595.

CHURCHILL Jr, G. A. (1979). A paradigm for developing better measures of marketing constructs. Journal of marketing research, 16(1), 64-73.

CIECHANOWSKI, L., PRZEGALINSKA, A., MAGNUSKI, M., \& GLOOR, P. (2019). In the shades of the uncanny valley: An experimental study of human-chatbot interaction. Future Generation Computer Systems, 92, 539-548. https://doi.org/10.1016/j. future.2018.01.055

CUI, L., HUANG, S., WEI, F., TAN, C., DUAN, C., \& ZHOU, M. (2017, July). Superagent: A customer service chatbot for e-commerce websites. In Proceedings of ACL 2017, System Demonstrations (pp. 97-102). 
DAMIANO, L., \& DUMOUCHEL, P. (2018). Anthropomorphism in human-robot co-evolution. Frontiers in psychology, 9, 468.

DEVELLIS, R. F. (2017). Scale development: Theory and applications. Los Angeles: SAGE.

DUIJST, D. (2017). Can we improve the user experience of chatbots with personalisation. Master's thesis. University of Amsterdam.

ELSHOLZ, E., CHAMBERLAIN, J., \& KRUSCHWITZ, U. (2019). Exploring Language Style in Chatbots to Increase Perceived Product Value and User Engagement. In L. Azzopardi, M. Halvey, I. Ruthven, H. Joho, V. Murdock, \& P. Qvarfordt (Eds.), Proceedings of the 2019 Conference on Human Information Interaction and Retrieval (pp. 301-305). New York, NY, USA: ACM. https://doi.org/10.1145/3295750.3298956

FINSTAD, K., (2010). Response interpolation and scale sensitivity: Evidence against 5-point scales. Journal of Usability Studies, 5(3), pp.104-110

FITZPATRICK, G. (2018). A short history of human computer interaction: A people-centred perspective. In Proceedings of the 2018 ACM SIGUCCS Annual Conference (pp. 3-3).

FØLSTAD, A., \& BRANDTZÆG, P. B. (2017). Chatbots and the new world of HCI. interactions, 24(4), 38-42.

FØLSTAD, A., NORDHEIM, C. B., \& BJØRKLI, C. A. (2018, October). What makes users trust a chatbot for customer service? An exploratory interview study. In International Conference on Internet Science (pp. 194-208). Springer, Cham.

GAETANO, S., \& DILIBERTO, P. (2018). Chatbots and conversational interfaces: Three domains of use. In Fifth International Workshop on Cultures of Participation in the Digital Age, Castiglione della Pescaia, Italy (Vol. 2101, pp. 62-70).

GENTSCH, P. (2018). Conversational AI: How (Chat)Bots Will Reshape the Digital Experience. AI in Marketing, Sales and Service, 81-125. doi:10.1007/978-3-319-89957-2_4

GNEWUCH, U., MORANA, S., \& MAEDCHE, A. (2017, December). Towards Designing Cooperative and Social Conversational Agents for Customer Service. In ICIS.

HINSON, R., BOATENG, H., RENNER, A., \& KOSIBA, J. P. B. (2019). Antecedents and consequences of customer engagement on Facebook. Journal of Research in Interactive Marketing.

HOLLEBEEK, L., (2011). Exploring customer brand engagement: definition and themes. Journal of strategic Marketing, 19(7), pp.555-573.

HONG, J. W., CHOI, S., \& WILLIAMS, D. (2020). Sexist AI: An Experiment Integrating CASA and ELM. International Journal of Human-Computer Interaction, 1-14.

HORI, C., PEREZ, J., HIGASHINAKA, R., HORI, T., BOUREAU, Y., INABA, M., . . KIM, S. (2019). Overview of the sixth dialog system technology challenge: DSTC6. Computer Speech \& Language, 55, 1-25. doi:10.1016/j.csl.2018.09.004

HUSSAIN, S., AMERI SIANAKI, O., \& ABABNEH, N. (2019). A Survey on Conversational Agents/Chatbots Classification and Design Techniques. In L. Barolli, M. Takizawa, F. Xhafa, \& T. Enokido (Eds.), Advances in Intelligent Systems and Computing. Web, Artificial Intelligence and Network Applications (Vol. 927, pp. 946-956). Cham: Springer International Publishing. https://doi. org/10.1007/978-3-030-15035-8_93
ISRAFILZADE, K. and PILELIENE, L., (2018). Can machines paint?. 5th International Multidisciplinary Scientific Conference on Social Sciences and Arts SGEM 2018, 18(6.3), pp. 109-116.

ISRAFILZADE, K. (2020). What's in a name? Experiment on the aesthetic judgments of art produced by artificial intelligence. Journal of Arts, 3(2), pp. 143-158.

ISRAFILZADE, K., \& BABAYEV, N. (2020). Millennial Versus Non-Millennial Users: Context Of Customer Engagement Levels On Instagram Stories (Extended Version). Journal of Life Economics, $7(2), 135-150$.

KRAFFT, M., Arden, C. M., \& Verhoef, P. C. (2017). Permission marketing and privacy concerns-Why do customers (not) grant permissions?. Journal of interactive marketing, 39, 39-54.

KULIGOWSKA, K. (2015). Commercial chatbot: performance evaluation, usability metrics and quality standards of embodied conversational agents. Professionals Center for Business Research, 2.

KUMAR, V., AKSOY, L., DONKERS, B., VENKATESAN, R., WIESEL, T., \& TILLMANNS, S. (2010). Undervalued or overvalued customers: capturing total customer engagement value. Journal of service research, 13(3), 297-310.

LEBEUF, C. R. (2018). A taxonomy of software bots: towards a deeper understanding of software bot characteristics

LECKIE, C., NYADZAYO, M. W., \& JOHNSON, L. W. (2016). Antecedents of consumer brand engagement and brand loyalty. Journal of Marketing Management, 32(5-6), 558-578.

LOCKE, C., LEVINE, R., SEARLS, D. and WEINBERGER, D., (2001). The cluetrain manifesto. Cambridge: Perseus Pub.

LUO, X., TONG, S., FANG, Z., \& QU, Z. (2019). Frontiers: Machines vs. humans: The impact of artificial intelligence chatbot disclosure on customer purchases. Marketing Science, 38(6), 937-947.

LYNN, M. R. (1986). Determination and quantification of content validity. Nursing research.

MASLOWSKA, E., MALTHOUSE, E. C., \& COLLINGER, T. (2016). The customer engagement ecosystem. Journal of Marketing Management, 32(5-6), 469-501.

MUIR, K., JOINSON, A., COTTERILL, R., \& DEWDNEY, N. (2017). Linguistic style accommodation shapes impression formation and rapport in computer-mediated communication. Journal of Language and Social Psychology, 36(5), 525-548.

NETEMEYER, R.G., Bearden, W.O. and Sharma, S., (2003). Scaling procedures: Issues and applications. Sage Publications.

NORMAN, K. L. (2017). Cyberpsychology: An introduction to human-computer interaction. Cambridge university press.

PFEUfFER, N., BENLIAN, A., GIMPEL, H., \& HINZ, O. (2019b). Anthropomorphic information systems. Business \& Information Systems Engineering, 61(4), 523-533.

RAMESH, K., RAVISHANKARAN, S., JOSHI, A., \& CHANDRASEKARAN, K. (2017, May). A survey of design techniques for conversational agents. In International Conference on Information, Communication and Computing Technology (pp. 336-350). Springer, Singapore.

SAYGIN, A. P., CHAMINADE, T., ISHIGURO, H., DRIVER, J., \& FRITH, C. (2011). The thing that should not be: Predictive 
coding and the uncanny valley in perceiving human and humanoid robot actions. Social Cognitive and Affective Neuroscience, 7(4), 413-422. doi:10.1093/scan/nsr025

SCHUETZLER, R. M., GRIMES, G. M., GIBONEY, J. S., \& BUCKMAN, J. (2014). Facilitating Natural Conversational Agent Interactions: Lessons from a Deception Experiment. Proceedings of the International Conference on Information Systems (ICIS), 1-16

SHUM, H. Y., HE, X. D., \& LI, D. (2018). From Eliza to XiaoIce: challenges and opportunities with social chatbots. Frontiers of Information Technology \& Electronic Engineering, 19(1), 10-26.

SO, K. K. F., KING, C., SPARKS, B. A., \& WANG, Y. (2016). Enhancing customer relationships with retail service brands: The role of customer engagement. Journal of Service Management, 27(2), 170-193.

SOTOLONGO, N., \& COPULSKY, J. (2018). Conversational marketing: Creating compelling customer connections. Applied Marketing Analytics, 4(1), 6-21.

THOMAS, E. (2020). EBay Partners With Google Assistant To Bring Voice Control To EBay's Android App. eBay Partners with Google Assistant to Bring Voice Control to eBay's Android App. https://tech.ebayinc.com/product/ebay-partners-with-google-assistant-to-bring-voice-control-to-ebays-android-app/.

THOMAZ, F., SALGE, C., KARAHANNA, E., \& HULLAND, J (2020). Learning from the Dark Web: leveraging conversational agents in the era of hyper-privacy to enhance marketing. Journal of the Academy of Marketing Science, 48(1), 43-63. https://doi. org/10.1007/s11747-019-00704-3
TOURÉ-TILLERY, M., \& MCGILL, A. L. (2015). Who or what to believe: Trust and the differential persuasiveness of human and anthropomorphised messengers. Journal of Marketing, 79(4), 94-110.

VAN PINXTEREN, M. M., WETZELS, R. W., RÜGER, J., PLUYMAEKERS, M., \& WETZELS, M. (2019). Trust in humanoid robots: implications for services marketing. Journal of Services Marketing.

WANG, X., \& YUAN, C. (2016). Recent Advances on Human-Computer Dialogue. CAAI Transactions on Intelligence Technology, 1(4), 303-312. doi:10.1016/j.trit.2016.12.004

XU, A., LIU, Z., GUO, Y., SINHA, V., \& AKKIRAJU, R. (2017). A new chatbot for customer service on social media. In Proceedings of the 2017 CHI Conference on Human Factors in Computing Systems (pp. 3506-3510).

YIN, Z., CHANG, K. H., \& ZHANG, R. (2017). Deepprobe: Information directed sequence understanding and chatbot design via recurrent neural networks. In Proceedings of the 23rd ACM SIGKDD International Conference on Knowledge Discovery and Data Mining (pp. 2131-2139).

YUSOFF, M. S. B. (2019). ABC of content validation and content validity index calculation. RESOURCE, 11(2).

ZADROZNY, W., BUDZIKOWSKA, M., CHAI, J., KAMBHATLA, N., LEVESQUE, S., \& NICOLOV, N. (2000). Natural language dialogue for personalised interaction. Communications of the ACM, 43(8), 116-120.

\section{APPENDIX}

Appendix 1. Narrowed-down list of the quality of CAUS dimensions and items

\begin{tabular}{|c|c|c|c|}
\hline No & Construct/dimension & No & Items \\
\hline 1 & $\begin{array}{l}\text { Anthropomorphism (human- } \\
\text { likeness) }\end{array}$ & $\begin{array}{r}1 \\
2 \\
3 \\
4 \\
5 \\
6 \\
7 \\
8 \\
9 \\
10 \\
11 \\
\end{array}$ & $\begin{array}{l}\text { Name } \\
\text { Age } \\
\text { Gender } \\
\text { Nationality } \\
\text { Appearance } \\
\text { Profession } \\
\text { Personality } \\
\text { Emotions } \\
\text { Self-presentation. } \\
\text { Professional appearance } \\
\text { Language style }\end{array}$ \\
\hline 2 & Personalized interaction & $\begin{array}{l}12 \\
13 \\
14 \\
15\end{array}$ & $\begin{array}{l}\text { Recommendation engines } \\
\text { 1-to-1 approach } \\
\text { Interpretation of the user request } \\
\text { Advice in the request of the user }\end{array}$ \\
\hline 3 & Permission marketing & $\begin{array}{l}16 \\
17 \\
\end{array}$ & $\begin{array}{l}\text { Data privacy } \\
\text { Trust }\end{array}$ \\
\hline 4 & Real-time interaction & $\begin{array}{l}18 \\
19 \\
20\end{array}$ & $\begin{array}{l}\text { Automated response } \\
7 / 24 / 365 \\
\text { Language (Keywords, Natural Language, } \\
\text { Conversation) }\end{array}$ \\
\hline 5 & CA types & $\begin{array}{l}21 \\
22 \\
23 \\
24\end{array}$ & $\begin{array}{l}\text { Knowledge-based } \\
\text { Goals } \\
\text { Design approach } \\
\text { Dynamism (static, dynamic) }\end{array}$ \\
\hline 6 & CA Platforms & $\begin{array}{l}25 \\
26 \\
27 \\
28\end{array}$ & $\begin{array}{l}\text { Social platforms (e.g., Facebook Messenger) } \\
\text { Ambient platforms (e.g., Alexa) } \\
\text { Live chat (e.g., the chatbot in website) } \\
\text { Standalone }\end{array}$ \\
\hline
\end{tabular}


Appendix 2. The relevance ratings on the item scale by ten experts

\begin{tabular}{|c|c|c|c|c|c|c|c|c|c|c|c|c|c|c|}
\hline \multirow[b]{2}{*}{ No } & \multirow{2}{*}{ Items } & \multicolumn{11}{|c|}{ Experts' results } & \multirow{2}{*}{$\begin{array}{l}\text { Expert. } \\
\text { agreed }\end{array}$} & \multirow{2}{*}{$\begin{array}{c}I- \\
C V I\end{array}$} \\
\hline & & 1 & 2 & 3 & 4 & 5 & 6 & 7 & 8 & 9 & 10 & 11 & & \\
\hline 1 & Name & 8 & 9 & 9 & 5 & 6 & 5 & 6 & 7 & 5 & 9 & 9 & 4 & 0.36 \\
\hline 2 & Age & 5 & 6 & 7 & 5 & 9 & 8 & 6 & 5 & 5 & 1 & & 1 & 0.09 \\
\hline 3 & Gender & 2 & 1 & 1 & 1 & 2 & 1 & 2 & 1 & 1 & 1 & 1 & $\mathbf{0}$ & 0.00 \\
\hline 4 & Nationality & 1 & 2 & 3 & 1 & 1 & 2 & 2 & 1 & 3 & 5 & 4 & $\mathbf{0}$ & 0.00 \\
\hline 5 & Appearance & 4 & 7 & 6 & 8 & 9 & 7 & 7 & 7 & 8 & 9 & 10 & 3 & 0.27 \\
\hline 6 & Profession & 5 & 5 & 2 & 5 & 9 & 8 & 6 & 6 & 7 & 8 & 9 & 2 & 0.18 \\
\hline 7 & Personality & 9 & 9 & 10 & 9 & 10 & 10 & 10 & 9 & 10 & 8 & 9 & 10 & 0.91 \\
\hline 8 & Emotions & 8 & 10 & 9 & 10 & 10 & 9 & 10 & 10 & 9 & 8 & 10 & 9 & 0.82 \\
\hline 9 & Self-presentation. & 7 & 10 & 9 & 8 & 9 & 6 & 9 & 9 & 7 & 9 & 10 & 7 & 0.64 \\
\hline 10 & $\begin{array}{l}\text { Professional } \\
\text { appearance }\end{array}$ & 10 & 9 & 10 & 10 & 9 & 10 & 10 & 10 & 9 & 8 & 10 & 10 & 0.91 \\
\hline 11 & Language style & 8 & 9 & 9 & 8 & 9 & 9 & 10 & 9 & 9 & 9 & 9 & 9 & 0.82 \\
\hline 12 & $\begin{array}{l}\text { Recommendation } \\
\text { engines }\end{array}$ & 10 & 10 & 9 & 8 & 10 & 10 & 10 & 9 & 10 & 10 & 8 & 9 & 0.82 \\
\hline 13 & 1-to-1 approach & 6 & 7 & 6 & 8 & 8 & 9 & 7 & 6 & 8 & 10 & 10 & 3 & 0.27 \\
\hline 14 & $\begin{array}{l}\text { Interpretation of the } \\
\text { user request }\end{array}$ & 10 & 9 & 8 & 10 & 10 & 10 & 9 & 10 & 10 & 9 & 9 & 10 & 0.91 \\
\hline 15 & $\begin{array}{l}\text { Advice in the request } \\
\text { of the user }\end{array}$ & 9 & 10 & 9 & 10 & 9 & 10 & 10 & 10 & 10 & 8 & 8 & 9 & 0.82 \\
\hline 16 & Data privacy & 9 & 10 & 9 & 8 & 10 & 10 & 10 & 9 & 10 & 10 & 8 & 9 & 0.82 \\
\hline 17 & Trust & 10 & 10 & 9 & 10 & 10 & 8 & 9 & 9 & 10 & 10 & 9 & 10 & 0.91 \\
\hline 18 & Automated response & 9 & 10 & 10 & 10 & 9 & 10 & 10 & 8 & 9 & 9 & 9 & 10 & 0.91 \\
\hline 19 & $7 / 24 / 365$ response & 9 & 10 & 9 & 9 & 9 & 9 & 10 & 8 & 9 & 9 & 8 & 10 & 0.91 \\
\hline 20 & $\begin{array}{l}\text { Language (Keywords, } \\
\text { Natural Language, } \\
\text { Conversation) }\end{array}$ & 7 & 8 & 7 & 6 & 7 & 6 & 9 & 7 & 8 & 8 & 9 & 2 & 0.18 \\
\hline 21 & Knowledge-based & 8 & 10 & 9 & 10 & 9 & 8 & 10 & 10 & 9 & 10 & 10 & 9 & 0.82 \\
\hline 22 & Goals & 9 & 9 & 9 & 10 & 10 & 9 & 8 & 10 & 10 & 9 & 9 & 10 & 0.91 \\
\hline 23 & Design approach & 8 & 10 & 10 & 9 & 10 & 10 & 9 & 9 & 10 & 8 & 9 & 9 & 0.82 \\
\hline 24 & $\begin{array}{l}\text { Dynamism (static, } \\
\text { dynamic) }\end{array}$ & 9 & 9 & 10 & 9 & 9 & 8 & 10 & 9 & 10 & 9 & 8 & 10 & 0.91 \\
\hline 25 & $\begin{array}{l}\text { Social platforms (e.g., } \\
\text { Facebook Messenger) }\end{array}$ & 9 & 10 & 9 & 9 & 8 & 10 & 10 & 10 & 9 & 9 & 9 & 10 & 0.91 \\
\hline 26 & $\begin{array}{l}\text { Ambient platforms } \\
\text { (e.g., Alexa) }\end{array}$ & 3 & 7 & 6 & 9 & 8 & 9 & 6 & 9 & 4 & 6 & 7 & 2 & 0.18 \\
\hline 27 & $\begin{array}{l}\text { Live chat (e.g., chatbot } \\
\text { in website) }\end{array}$ & 8 & 9 & 8 & 9 & 7 & 8 & 9 & 10 & 8 & 8 & 10 & 5 & 0.45 \\
\hline 28 & Standalone & 3 & 7 & 5 & 6 & 4 & 7 & 9 & 7 & 7 & 8 & 7 & 1 & 0.09 \\
\hline & & & & & & & & & & & & & CVI/Ave & 0.59 \\
\hline
\end{tabular}

Appendix 3. Descriptive statistics of each element of the quality of the conversational agent's usage scale (CAUS) instrument, Pilot study.

\begin{tabular}{|c|c|c|c|c|c|}
\hline Item & Item coding & Mean & $\begin{array}{l}\text { Std. } \\
\text { Dev. }\end{array}$ & $\begin{array}{l}\text { Skewnes } \\
\text { s }\end{array}$ & $\begin{array}{l}\text { Kurtosi } \\
\text { s }\end{array}$ \\
\hline Personality & ANT_PERSON & 5.40 & 1.305 & -1.046 & 1.519 \\
\hline Emotions & ANT_EMOTIO & 5.31 & 1.171 & -0.749 & 0.517 \\
\hline Professional appearance & ANT_APPEAR & 5.09 & 1.210 & -0.533 & -0.125 \\
\hline Language style & ANT_LANGUA & 5.45 & 1.217 & -0.627 & -0.021 \\
\hline Recommendation engines & PER_RECOMM & 5.57 & 0.875 & -0.004 & -0.675 \\
\hline $\begin{array}{r}\text { Interpretation of the user } \\
\text { request }\end{array}$ & PER_INTERPE & 5.55 & 0.951 & -0.221 & -0.255 \\
\hline $\begin{array}{r}\text { Advice in the request of the } \\
\text { user }\end{array}$ & PER_ADVICE & 5.72 & 0.860 & -0.262 & -0.516 \\
\hline Automated response & PER_AUTOMA & 5.69 & 0.944 & -0.518 & 0.035 \\
\hline 7/24/365 response & PER_NONS & 3.90 & 1.411 & -0.435 & -0.577 \\
\hline Data privacy & PMA_DATAPR & 5.51 & 1.020 & -0.289 & 0.046 \\
\hline Trust & PMA_TRUST & 5.62 & 0.957 & -0.191 & -0.576 \\
\hline Knowledge-based & CA_KNNOWLE & 5.61 & 1.033 & -0.327 & -0.605 \\
\hline Goals & CA_GOALS & 5.58 & 1.025 & -0.549 & 0.405 \\
\hline Design approach & CA_DESIGN & 5.42 & 1.007 & -0.119 & -0.415 \\
\hline Dynamism (static, dynamic) & CA_DYNAMI & 4.06 & 1.460 & -0.347 & -0.580 \\
\hline $\begin{array}{l}\text { Social platforms (e.g., } \\
\text { Facebook Messenger) }\end{array}$ & CA_SOCPLA & 5.35 & 1.118 & -0.695 & 1.165 \\
\hline
\end{tabular}


Appendix 4. KMO and Bartlett's Test of Pilot Study

\begin{tabular}{l|l|r}
\hline \multicolumn{2}{l}{ Kaiser-Meyer-Olkin Measure of Sampling Adequacy. } \\
\hline Bartlett's Test of Sphericity & Approx. Chi-Square & 0.808 \\
& df & 949.827 \\
& Sig. & 120 \\
\hline
\end{tabular}

Appendix 5. Communalities, Pilot Study

\begin{tabular}{|l|r|r|}
\hline & \multicolumn{1}{|c|}{ Initial } & Extraction \\
\hline ANT_PERSON & .749 & .853 \\
\hline ANT_EMOTIO & .634 & .692 \\
\hline ANT_APPEAR & .612 & .630 \\
\hline ANT_LANGUA & .591 & .594 \\
PER_RECOMM & .631 & .664 \\
PER_INTERPE & .714 & .833 \\
\hline PER_ADVICE & .710 & .678 \\
\hline PER_AUTOMA & .681 & .629 \\
\hline PER_NONS & .214 & .479 \\
\hline PMA_DATAPR & .663 & .749 \\
\hline PMA_TRUST & .686 & .811 \\
\hline CA_KNOWLE & .697 & .806 \\
\hline CA_GOALS & .663 & .598 \\
\hline CA_DESIGN & .564 & .613 \\
\hline CA_DYNAMI & .181 & .346 \\
\hline CA_SOCPLA & .617 & .652 \\
\hline
\end{tabular}

Extraction Method: Principal Axis Factoring.
Appendix 6. Total Variance Explained, Pilot Study

\begin{tabular}{|c|c|c|c|c|c|c|}
\hline \multirow[b]{2}{*}{ Factor } & \multicolumn{3}{|c|}{ Initial Eigenvalues } & \multicolumn{3}{|c|}{ Extraction Sums of Squared Loadings } \\
\hline & Total & $\begin{array}{c}\% \text { of } \\
\text { Variance }\end{array}$ & $\begin{array}{c}\text { Cumulative } \\
\%\end{array}$ & Total & $\begin{array}{c}\% \text { of } \\
\text { Variance }\end{array}$ & $\begin{array}{c}\text { Cumulative } \\
\%\end{array}$ \\
\hline 1 & 5.720 & 35.749 & 35.749 & 5.417 & 33.857 & 33.857 \\
\hline 2 & 2.302 & 14.389 & 50.138 & 2.009 & 12.557 & 46.414 \\
\hline 3 & 1.638 & 10.238 & 60.376 & 1.363 & 8.518 & 54.931 \\
\hline 4 & 1.405 & 8.780 & 69.157 & 1.034 & 6.465 & 61.396 \\
\hline 5 & 1.272 & 7.951 & 77.107 & .804 & 5.025 & 66.422 \\
\hline 6 & .623 & 3.895 & 81.002 & & & \\
\hline 7 & .551 & 3.444 & 84.446 & & & \\
\hline 8 & .506 & 3.165 & 87.611 & & & \\
\hline 9 & .392 & 2.452 & 90.063 & & & \\
\hline 10 & .310 & 1.937 & 92.000 & & & \\
\hline 11 & .301 & 1.884 & 93.884 & & & \\
\hline 12 & .267 & 1.670 & 95.554 & & & \\
\hline 13 & .223 & 1.397 & 96.951 & & & \\
\hline 14 & .200 & 1.248 & 98.199 & & & \\
\hline 15 & .149 & .934 & 99.133 & & & \\
\hline 16 & .139 & .867 & 100.000 & & & \\
\hline
\end{tabular}

Extraction Method: Principal Axis Factoring.

Appendix 7. Total Variance Explained

\begin{tabular}{c|l|l|l|l|l|l}
\hline \multirow{2}{*}{ Factors } & \multicolumn{2}{|l|}{ Extraction Sums of Squared Loadings } & \multicolumn{3}{|l}{ Rotation Sums of Squared Loadings } \\
\cline { 2 - 7 } & Total & \% of Variance & Cumulative \% & Total & \% of Variance & Cumulative \% \\
1 & 5.39 & 38.47 & 38.47 & 2.84 & 20.29 & 20.29 \\
2 & 2.01 & 14.33 & 52.79 & 2.66 & 18.98 & 39.27 \\
3 & 1.36 & 9.68 & 62.47 & 2.65 & 18.95 & 58.22 \\
4 & 1.02 & 7.28 & 69.75 & 1.62 & 11.53 & 69.75 \\
\hline
\end{tabular}

Extraction Method: Principal Axis Factoring.

Appendix 8. Descriptive statistics of each element of the quality of the conversational agent's usage (CAU) instrument (2nd Study).

\begin{tabular}{r|r|r|r|r}
\hline Item & \multicolumn{1}{|l|}{ Mean } & Std. Deviation & \multicolumn{1}{|l}{ Skewness } & Kurtosis \\
\hline ANT_PERSON & 5.3566 & 1.29683 & -0.671 & -0.028 \\
ANT_EMOTIO & 5.2587 & 1.14887 & -0.692 & 0.516 \\
ANT_APPEAR & 5.3427 & 1.3221 & -1.044 & 1.406 \\
ANT_LANGUA & 5.1329 & 1.1336 & -0.53 & 0.33 \\
PER_RECOMM & 5.5385 & 0.88627 & 0.067 & -0.719 \\
PER_INTERPE & 5.6294 & 0.89347 & -0.217 & -0.658 \\
PER_ADVICE & 5.4965 & 0.93352 & -0.095 & -0.387 \\
PER_AUTOMA & 5.6364 & 0.96812 & -0.487 & -0.139 \\
PMA_DATAPR & 5.4895 & 1.02687 & -0.466 & 0.443 \\
PMA_TRUST & 5.5734 & 0.96771 & -0.234 & -0.498 \\
CA_KNOWLE & 5.3147 & 1.17737 & -0.767 & 1.207 \\
CA_GOALS & 5.5385 & 1.06658 & -0.543 & 0.073 \\
CA_DESIGN & 5.4056 & 1.03623 & -0.148 & -0.471 \\
CA_SOCPLA & 5.5734 & 1.03794 & -0.256 & -0.794 \\
\hline
\end{tabular}

Appendix 9. Total Variance Explained

\begin{tabular}{|c|c|c|c|}
\hline \multirow[t]{2}{*}{ Factor } & \multicolumn{3}{|c|}{ Rotation Sums of Squared Loadings } \\
\hline & Total & $\%$ of Variance & Cumulative $\%$ \\
\hline 1 & 2.850 & 20.360 & 20.360 \\
\hline 2 & 2.832 & 20.228 & 40.588 \\
\hline 3 & 2.540 & 18.142 & 58.730 \\
\hline 4 & 1.592 & 11.373 & 70.103 \\
\hline
\end{tabular}

